\title{
Epidemiology
}

\section{Pasteurisation and the control of milkborne infection in Britain}

\author{
J C M SHARP， G M PATERSON, NICOLA J BARRETT
}

\begin{abstract}
Infections carried in milk, particularly salmonellosis and campylobacter enteritis, have continued to feature in Great Britain in recent years. Less commonly reported infections included an outbreak in 1984 in England due to Streptococcus zooepidemicus, in which 12 people, eight of whom died, were admitted to hospital.

The implementation of legislation in 1983 requiring heat treatment of cows' milk for sale to the public reduced the incidence of milkborne infection in Scotland compared with previous years and compared with England and Wales, where, without legislative control, outbreaks continue to occur. Until compulsory pasteurisation is introduced throughout Britain and dairy farming communities can be persuaded to drink only heat treated milk outbreaks of milkborne infection will continue.
\end{abstract}

\section{Introduction}

The role of milk and dairy products in the transmission of communicable disease has been highlighted in recent years in Great Britain $^{1-6}$ and other developed countries such as the United States ${ }^{78}$ and Canada. ${ }^{9}$ As a result of successful programmes to eradicate disease in cattle tuberculosis and brucellosis no longer feature as milkborne diseases in Britain. Other bovine infections, however, such as with salmonella and campylobacter, which do not lend themselves readily to veterinary control, continue to cause considerable morbidity, particularly among consumers of raw milk.

Milkborne salmonellosis was particularly serious in Scotland during the 1970s and early 1980s, when 50 outbreaks affecting at least 3518 people, of whom 12 died, were recorded.${ }^{14}$ In addition, several major outbreaks of campylobacter infection were reported. ${ }^{111}$ Smaller outbreaks of salmonellosis were also experienced concurrently in England and Wales, ${ }^{2}$ along with episodes of milkborne campylobacter infection ${ }^{12}$ and sore throat due to Corynebacterium ulcerans. ${ }^{1314}$ The resultant economic loss to the community and the dairy industry was considerable. A cost benefit study of a large outbreak of salmonellosis with two deaths in north east Scotland in 1981 estimated a total minimum cost of $£ 236000$ and a maximum of $£ 3222000$, with a mid-range average cost per patient of $£ 2637 .^{15}$

This paper draws attention to the success achieved in Scotland over the past two years after the introduction in August 1983 of

Communicable Diseases (Scotland) Unit, Ruchill Hospital, Glasgow G20 9NB J C M SHARP, MB, FFCM, consultant epidemiologist

Department of Agriculture and Fisheries for Scotland, Glasgow G1 3JP G M PATERSON, NDD, SDDH, food and dairy officer

Communicable Disease Surveillance Centre, Public Health Laboratory Service, London NW9 5EQ

NICOLA J BARRETT, PHD, ARCS, research assistant

Correspondence to: Dr J C M Sharp. legislation requiring heat treatment of cows' milk for sale to the public ${ }^{16}$ compared with the situation in England and Wales, where milkborne infection has remained a problem and will continue to be so until control measures are implemented.

\section{Method}

Surveillance of infections borne by food, including those attributed to milk and dairy products, is undertaken nationally in Scotland at the Communicable Diseases (Scotland) Unit and in England and Wales at the Public Health Laboratory Service Communicable Disease Surveillance Centre. Information concerning incidents of infection was obtained from routine returns submitted by microbiological laboratories and epidemiological reports from community physicians and environmental health officers throughout Britain. Confirmation of milkborne infection usually depended on isolation of the causative organism from patients and from cattle, milk, or milk filters on the implicated farms. In the absence of supportive microbiological results several incidents were accepted on the basis of strong epidemiological evidence.

\section{Results}

\section{ENGLAND AND WALES}

Twenty outbreaks of milkborne salmonellosis affecting at least 518 people were reported during 1983-4; in 19 raw milk was implicated, and in the other episode (in which five people were taken ill) contaminated pasteurised milk was implicated. This compares with $1980-2$, when 540 cases were associated with 40 outbreaks. Twelve of the outbreaks in 1983-4 affected consumers in the general community who had purchased untreated milk from local producer-retailer dairy farms; the two largest outbreaks affected 182 and 106 people respectively. The remainder affected people living in dairy farming communities who had been drinking raw milk from their own herds. One other incident in 1983 affected two members of a farming community, who were taken ill after eating home produced cream; Salmonella typhimurium phage type 49 was isolated from milk filters at the farm, from both raw and pasteurised cream, and from three asymptomatic dairy workers.

Untreated milk was implicated as the vehicle of infection in six cutbreaks of campylobacter enteritis in 1983-4; 10 other reported incidents yielded insufficient microbiological and epidemiological evidence to be considered in the analysis. At least 161 people were affected in the six outbreaks, the largest of which affected 54 people in three villages. During the previous three years 17 outbreaks comprising at least 1006 cases had been reported.

The most notable event attributed to consumption of raw milk during the past two years was an outbreak of Streptococcus zooepidemicus; of 12 people admitted to hospital, eight died. The causative organism was isolated from milk supplied by a farm where several cattle were found to be excreting $S t r$ zooepidemicus in their milk. Comparable milkborne infections due to this organism have not previously been reported in Britain, although a few smaller incidents have occurred in which raw milk was a possible vehicle of infection. ${ }^{17}$

Other milkborne episodes reported during 1983-4 included two sporadic cases of $C$ ulcerans infection; one patient had been immunised as a child, and neither patient contracted toxigenic strains of the organism. Raw milk from a pet goat was implicated in one instance, although the organism was not isolated from the milk.

Three people at a nursing home, including an asymptomatic member of staff found to be excreting the organism, were affected in an incident due to Yersinia enterocolitica. Contaminated pasteurised milk was implicated, and 
routine samples of pasteurised milk from retail outlets in the area during 1984 were positive for yersinia. A bulk holding tank at the pasteurisation plant was suggested as the source of contamination, and samples of pasteurised milk obtained after cleaning proved negative. No other cases of infection were reported.

\section{SCOTLAND}

Eight outbreaks of milkborne salmonellosis affecting 46 people in dairy farming communities were recorded during 1983-4. No outbreaks due to milkborne infection were reported from the general community. This contrasted appreciably with the experience in the previous three years, when 14 general outbreaks of varying sizes affecting over 1090 cases had occurred.

Two household episodes of campylobacter enteritis attributed to drinking raw milk were recorded in 1983 and none in 1984. One of these occurred at a caravan site before August 1983, and the other affected a family who had returned from holiday in south west England.

One other incident affected two people, who became ill after consuming raw cream given by a farming friend; typical Escherichia coli organisms were cultured from the cream.

\section{Discussion}

Milk is a valuable source of human nutrition but also provides an excellent culture medium for the growth of micro-organisms; salmonellas, coliforms, and other organisms are often cultured from dairy products, particularly raw milk, in Britain. Although many contaminating organisms only spoil the products, others are pathogenic to man and may cause infection if the milk is untreated. Unlike poultry and other meats that may be contaminated, milk is less likely to be subjected to any subsequent heating before consumption. The high fat content of milk also affords protection to pathogens against gastric acid, while its fluid nature ensures a fairly short exposure time in the stomach. As few as 500 campylobacter organisms in $180 \mathrm{ml}$ of milk can cause illness in man. ${ }^{18}$

Pasteurisation has been used for many years in the heat treatment of various foodstuffs. The introduction of mandatory pasteurisation of raw ice cream mix in 1948 and of liquid egg in 1964 effectively eliminated these food items as vehicles of infection in Britain. More recently, legislation relating to the heat treatment of cream and milk based drinks was introduced in November 1983, although this did little more than consolidate what had been, commercially, almost universal practice since the end of the second world war. The fact that cream is rarely a vehicle of infection is undoubtedly due to this treatment.

Pasteurisation of cows' milk in Scotland has been similarly effective since 1983 in reducing milkborne infection. Although temporary exemptions allowing the sale of untreated milk have been granted to a few small dairy farms located on several outer islands, their production represents less than $0.02 \%$ of total milk sales in Scotland. Of greater concern is the continuing provision of raw milk to the staff of dairy farms and their families, a practice not prohibited by the 1983 legislation as no retail sale occurs. Outbreaks on farms will continue to occur until those at risk can be persuaded to drink only heat treated milk.

In contrast with the situation in Scotland during 1983-4, outbreaks associated with the consumption of raw milk still caused considerable morbidity in England and Wales. Of particular concern is the increasing number of outbreaks of salmonellosis in the general community over the past five years affecting people who had purchased raw milk distributed by local dairy farms. Although less than $3 \%$ of the 6000 million litres of milk sold each year in England and Wales is untreated, half of this is produced in the north western region of the Milk Marketing Board, with $39 \%$ of all producer-retailers of raw milk located in Lancashire and West Yorkshire. ${ }^{19}$ It is therefore not surprising that $70 \%$ of all milkborne outbreaks reported during 1983-4 occurred in the corresponding regional health authorities of the National Health Service-namely, North Western and Yorkshire. Legislation due to come into force in November $1985^{20}$ should reduce the incidence of milkborne infection in England and Wales, as has been the case in Scotland, by restricting the availability of untreated milk from shops and other retail outlets. In contrast with the legislation in Scotland, however, sales direct from the farm and local retail deliveries of raw milk bottled on farms will not be prohibited, so that many rural communities in addition to dairy farming ones will remain at risk from milkborne infection.

The sale of untreated goats' milk and sheep's milk is not prohibited anywhere in Britain as current legislation applies only to cows' milk. A variety of organisms such as coagulase negative and coagulase positive staphylococci, streptococci, $E$ coli, $Y$ enterocolitica, and campylobacter have been found in surveys of goats' milk,,$^{21} 22$ and occasional episodes of infection in man associated with drinking unpasteurised products may therefore be expected.

High standards of dairy hygiene and heat treatment of milk are complementary to each other and not mutually exclusive. Organisms that bear spores such as Bacillus cereus (Public Health Laboratory Service Communicable Disease Surveillance Centre) or Clostridium perfringens ${ }^{5}$ may survive pasteurising temperatures but do not appear to be an appreciable cause of illness in Britain. Furthermore, pasteurisation may not be fully effective in the presence of large inoculums of micro-organisms ${ }^{23}$ Contamination of milk after pasteurisation may arise in inadequately maintained plants and has resulted in occasional outbreaks such as the two episodes of salmonellosis and yersiniosis in England during 1983-4. In addition, failure to pasteurise as a result of mechanical or electrical breakdown, although rare, has led to outbreaks of infection due to campylobacter ${ }^{10}{ }^{12}$ and $C$ ulcerans. ${ }^{13}$

Nevertheless, most outbreaks are related to drinking raw milk rather than contaminated heat treated milk. Our results show that the introduction of legislation in 1983 prohibiting the sale of untreated milk in Scotland has been highly effective in controlling milkborne infection, in contrast with the situation in England and Wales. Until comprehensive pasteurisation of all milk and dairy products is implemented throughout Britain, milkborne infections will continue to cause considerable morbidity and economic loss.

We acknowledge the advice and encouragement given by Dr G I Forbes, Scottish Home and Health Department, and Dr N S Galbraith, PHLS Communicable Disease Surveillance Centre, in the preparation of this paper, and thank Mrs M Graham for secretarial help.

\section{References}

1 Sharp JCM, Paterson GM, Forbes GI. Milk-borne salmonellosis in Scotland. Fournal of Infection $1980 ; 2: 333-40$

2 Galbraith NS, Forbes P, Clifford C. Communicable disease associated with milk and dairy products in England and Wales 1951-80. Br Med f 1982;284:1761-5.

3 PHLS Communicable Disease Surveillance Centre. Disease attributed to dairy products. $\mathrm{Br}$ Med J 1982;285:1664

4 Reilly WJ, Sharp JCM, Forbes GI, Paterson GM. Milkborne salmonellosis in Scotland 1980 to 1982. Vet Rec 1983;112:578-80.

5 Galbraith NS, Pusey JJ. Milkborne infectious disease in England and Wales 1938-1982. In: Freed DLJ, ed. Health hazards of milk. Eastbourne: Baillière-Tindall, 1984

6 PHLS Communicable Disease Surveillance Centre. Disease associated with milk and dairy products: 1982. Br Med f 1984;288:466-7.

7 Bryan FL. Epidemiology of milk-borne diseases. Journal of Food Protection 1983;46:637-49.

8 Potter ME, Kaufmann AF, Blake PA, Feldman RA. Unpasteurised milk: the hazards of a health fetish. FAMA 1984;252:2048-52.

9 White FMM, McCarthy ME. Raw milk and health in humans. Can Med Assoc $\mathcal{f}$ 1982;126:1260-2.

10 Porter IA, Reid TMS. A milk-borne outbreak of campylobacter infection. Foumal of Hygiene (Cambridge) 1980;84:415-9.

11 Wallace JM. Milk-associated campylobacter infection. Health Bull (Edinb) 1980;38:57-61

12 Robinson DA, Jones DM. Milkborne campylobacter infection. Br Med f 1981;282:1374-6.

13 Hart RJC. Corynebacterium ulcerans in humans and cattle in north Devon. Journal of Hygiene Cambridge) 1984;92:161-4.

14 Bostock AD, Gilbert FR, Lewis D, Smith DCM. Corynebacterium ulcerans infection associated with untreated milk. Fournal of Infection 1984;9:286-8.

15 Cohen DR, Porter IA, Reid TMS, Sharp JCM, Forbes GI, Paterson GM. A cost benefit study of milk-borne salmonellosis. Fourmal of Hygiene (Cambridge) 1983;91:17-23.

16 Statutory Publications Office. The milk (special designations) (Scotland) order 1980. Edinburgh: HMSO, 1980. (Statutory Instruments 1980 No 1866 (S168).)

17 Barnham M, Thornton TJ, Lange K. Nephritis caused by Streptococcus zooepidemicus (Lancefield group C). Lancet 1983;i:945-8.

18 Robinson DA. Infective dose of Campylobacter jejuni in milk. Br Med 7 1981:282:1584

19 Federation of Milk Marketing Boards. UK dairy facts and figures, 1984. Thames Ditton: Federation of UK Milk Marketing Boards, 1985.

20 Statutory Publications Office. The milk (special designations) (amendment) regulations 1985. London: HMSO, 1985. (Statutory Instruments 1985 No 530 .)

21 Roberts D. Microbiological aspects of goat's milk. A Public Health Laboratory Service survey. fournal of Hygrene (Cambridge) 1985;94:31-44.

22 Hunter AC. Microflora and somatic cell content of goat milk. Vet Rec 1984;114:318-20.

23 Fleming DW, Cochi SL, MacDonald KL, et al. Pasteurized milk as a vehicle of infection in an outbreak of listeriosis. N Engl f Med 1985;312:404-7.

(Accepted 20 May 1985) 